\title{
Antiinflammatory Activity of Astilbic Acid from Astilbe chinensis
}

\author{
Tae Chul Moon, ${ }^{a}$ Chang Xiu Lin, ${ }^{a}$ Joo Sang Lee, ${ }^{a}$ Dong Seon KIm, ${ }^{b}$ KiHwan BAE, ${ }^{c}$ Kun Ho Son, ${ }^{d}$ \\ Hyun Pyo Kim, ${ }^{e}$ Sam Sik Kang, ${ }^{f}$ Jong Keun Son, ${ }^{a}$ and Hyeun Wook CHAnG ${ }^{*}, a$ \\ ${ }^{a}$ College of Pharmacy, Yeungnam University; 712-749, Gyongsan, Korea: ${ }^{b}$ UNIGEN, Songjung-Ri, Byeongchen-Myeon; \\ Cheonan-Si, Chungnam 330-863, Korea: ${ }^{c}$ College of Pharmacy, Chungnam National University; Daejon 305-764, Korea: \\ ${ }^{d}$ Department of Food and Nutrition, Andong National University; Andong 760-749, Korea: ${ }^{e}$ College of Pharmacy, \\ Kangwon National University; Chunchen 200-749, Korea: and ${ }^{f}$ Natural Products Research Institute, Seoul National \\ University; Seoul 110-460, Korea. Received August 24, 2004; accepted October 5, 2004
}

This study examined the effect of astilbic acid $(3 \beta, 6 \beta$-dihydroxyolean-12-en-27-oic acid), which is a herbal medicine isolated from Astilbe chinensis. Astilbic acid inhibited 5-lipoxygenase (5-LOX)-dependent leukotriene $\mathrm{C}_{4}\left(\mathrm{LTC}_{4}\right)$ generation in bone marrow-derived mast cells in a concentration-dependent manner with an $\mathrm{IC}_{50}$ value of $2.1 \mu \mathrm{M}$. In addition, astilbic acid was tested in a rat passive cutaneous anaphylaxis (PCA) reaction assay by administering 10 to $50 \mathrm{mg} / \mathrm{kg}$ i.p. Astilbic acid dose dependently inhibited the PCA reaction, which was activated by anti-dinitrophenyl (DNP) IgE. Furthermore, this compound inhibited mouse acetic acid-induced writhing $(47-62 \%$ inhibition at $0.4-50 \mathrm{mg} / \mathrm{kg})$ after being administered orally, while aspirin $(200 \mathrm{mg} / \mathrm{kg})$ showed $62 \%$ inhibition. These results suggest that astilbic acid may be beneficial in regulating various inflammatory processes.

Key words Astilbe chinensis; astilbic acid; 5-lipoxygenase; mouse bone marrow-derived mast cell; passive cutaneous anaphylaxis; analgesic activity

Eicosanoids including prostaglandins (PGs) and leukotrienes (LTs) are inflammatory mediators. 5-Lipoxygenase (5-LOX), which is present in white blood cells, macrophages, and mast cells, is the rate-limiting enzyme for the synthesis of LTs. The cysteinyl LTs are potent mediators of allergy and inflammation by modulating the smooth muscle tone and vascular permeability. In addition, they play an important role in asthma and other respiratory diseases. ${ }^{1-3)}$ Furthermore, the products of lipoxygenases cause hyperalgesia when injected intradermally. $\left.{ }^{4}{ }^{6}\right) \mathrm{LTC}_{4}$ and $\mathrm{LTD}_{4}$ cause renal vasoconstriction, mesangial cell contraction, and proliferation, as well as production of extracellular matrix proteins. ${ }^{7-10)}$ LTB $_{4}$ stimulates chemotaxis and leukocyte adhesion to endothelial cells and modulates the production of interleukin (IL)-1 and tumor necrosis factor- $\alpha$ (TNF- $\alpha)^{11,12)}$

Astilbe chinensis is a perennial herb that grows in China, Russia, Japan, and Korea (Fig. 1). The dried roots of $A$. chinensis have been used in Korean traditional medicine to treat headaches and bronchitis, as well as being used as an antipyretic and analgesic remedy. However, the underlying mechanisms of its antiinflammatory effects have not been reported. To the best of our knowledge, this paper reports for the first time the inhibitory activity of astilbic acid on 5LOX-dependent $\mathrm{LTC}_{4}$ generation along with its antiinflammatory and analgesic activity in an in vivo animal model.

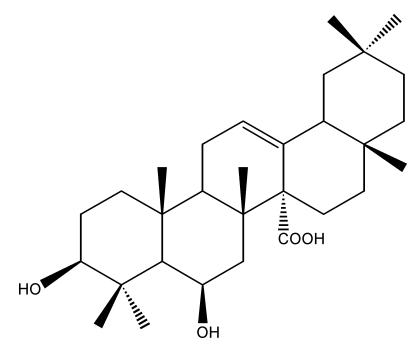

Fig. 1. Chemical Structure of Astilbic Acid

\section{MATERIALS AND METHODS}

Materials The dried roots of $A$. chinensis $(1.3 \mathrm{~kg})$ were extracted using $\mathrm{MeOH}(\mathrm{v} / \mathrm{v}, 5 \mathrm{ml})$ at room temperature for $7 \mathrm{~d}$ to obtain an extract $(120 \mathrm{~g})$. The extract was resuspended in water $(1 \mathrm{ml})$ and partitioned with the same volume of hexane. The $n$-hexane-soluble fraction $(9 \mathrm{~g})$ was applied to a silica gel column $(63-200$ mesh, $5 \times 60 \mathrm{~cm})$ and eluted with hexane/EtOAc $(10: 1-1: 2$, gradient) to give eight fractions (fr. 1 to fr. 8). Fraction 5 (1.1 g) was repeatedly chromatographed over silica gel $\left(2.5 \times 40 \mathrm{~cm}\right.$, eluate: $\mathrm{CHCl}_{3} / \mathrm{MeOH}$, $30: 1$ ) to give four subfractions (fr. 5-1 to fr. 5-4). Fraction 5-3 (170 mg) was recrystallized in $\mathrm{MeOH}$ to give a white needles $(60 \mathrm{mg})$. Astilbic acid ( $3 \beta, 6 \beta$-dihydroxyolean-12-en27-oic acid) $\mathrm{mp} 206-209^{\circ} \mathrm{C}$, mass $\left(\mathrm{M}^{+}, \mathrm{m} / \mathrm{e}\right.$ 472). Anal. Calcd for $\mathrm{C}_{30} \mathrm{H}_{48} \mathrm{O}_{4}$ : C, $76.27 \%$; $\mathrm{H}, 10.17 \%$. Found: $\mathrm{C}$, $\left.76.11 \% ; \mathrm{H}, 10.09 \%,[\alpha]_{\mathrm{D}}^{20}+103^{\circ}\left(c=1.0, \mathrm{CHCl}_{3}\right)\right] \cdot{ }^{13)}{ }^{1} \mathrm{H}-$ NMR $1.68(\mathrm{~s}), 0.88(\mathrm{~s}), 1.26(\mathrm{~s}), 1.02(\mathrm{~s}), 1.02(\mathrm{~s}), 1.70(\mathrm{~s})$, $1.72(\mathrm{~s}) ; \mathrm{CH}_{3} \times 7,1.25(\mathrm{~m}), 1.74(\mathrm{~m}), 1.80$ (dd like), $2.05(\mathrm{~m})$, 2.23 (m) 2.47 (m) 2.91 (dd) 4.84 (br s), 3.30 (dd, $J=4.2$, $5.4 \mathrm{~Hz}$ ), 5.85 (brs). Astilbic acid was previously isolated from two plants. ${ }^{13,14}$ Fetal bovine serum was purchased from Hyclone Laboratories (Logan, UT, U.S.A.). Astilbic acid was dissolved in dimethyl sulfoxide (DMSO) before addition to cell cultures; the final concentration of DMSO was $0.05 \%$. Control experiments with DMSO alone were performed in all cases.

Preparation and Activation of Bone Marrow-Derived Mast Cells Bone marrow derived-mast cells (BMMCs) from male Balb/cJ mice were cultured for up to 10 weeks in $50 \%$ enriched medium (RPMI 1640 containing $2 \mathrm{~mm}$ L-glutamine, nonessential amino acids $0.1 \mathrm{~nm}$, antibiotics, and $10 \%$ fetal calf serum) and 50\% WEHI-3 cell-conditioned medium as a source of IL-3. After 3 weeks, $>98 \%$ of the cells were found to be BMMCs as determined using the previously described procedure. ${ }^{15,16)}$ For measuring inhibitory activity of 5-LOX by astilbic acid, cells suspended at a density of 
$1 \times 10^{6}$ cells $/ \mathrm{ml}$ in enriched medium were preincubated with stem cell factor $\left(\mathrm{SCF} ; 100 \mathrm{ng} / \mathrm{ml}\right.$ ) for $30 \mathrm{~min}$ at $37^{\circ} \mathrm{C}$ in the presence or absence of astilbic acid. After 20 min of stimulation, the supernatants were isolated for further analysis with an enzyme immunoassay kit (EIA). LTC $_{4}$ was determined using an EIA kit (Cayman Chemical, Ann Arbor, MI, U.S.A.) according to the manufacturer's instruction. Under the conditions employed, $\mathrm{LTC}_{4}$ reached about $500 \mathrm{pg} / 10^{6}$ cells. All data are the arithmetic mean of triplicate determinations.

Passive Cutaneous Anaphylaxis Male Sprague-Dawley rats (Daehan Biolink, Eumsung, Korea) weighing 180$200 \mathrm{~g}$ were used in the passive cutaneous anaphylaxis (PCA) test. The animals were housed in cages at least 1 week prior to the experiments. Briefly, $100 \mu \mathrm{l} /$ site of monoclonal antidinitrophenyl (DNP) mouse IgE (1:1000 dilution; Seikagaku-kougyo, Japan) was injected intradermally into the shaved backs of rats. After $48 \mathrm{~h}$, PCA was evoked by an intravenous injection of the antigen (Ag; $1 \mathrm{mg}$ of DNP-bovine serum albumin (BSA) (Sigma Chemical Co.)) in phosphatebuffered saline (PBS) containing $1 \mathrm{ml}$ of $1 \%$ Evans blue $(1: 4)$. Astilbic acid $(10-50 \mathrm{mg} / \mathrm{kg}$ body weight i.p.) and indomethacin $(1-10 \mathrm{mg} / \mathrm{kg}$ i.p.) were administered $1 \mathrm{~h}$ before the Ag challenge. After $30 \mathrm{~min}$, the skin was removed and dye was leaked into the skin, which was then extracted and quantified, as described previously. ${ }^{17)}$ At doses up to $20 \mathrm{mg} / \mathrm{kg}$, this compound did not show any toxicity such as decreased body weight and no morphologic changes in the spleen and liver were seen.

Analgesic Activity To measure analgesic activity, the standard acetic acid-induced writhing test was employed according to the previously described procedure. ${ }^{18)}$ Astilbic acid and aspirin were orally administrated to mice. One hour later, $100 \mu \mathrm{l}$ of acetic acid (0.7\%) was administered intraperitoneally and the number of writhing movements was counted for $10 \mathrm{~min}$ starting $10 \mathrm{~min}$ after the administration of acetic acid solution.

Statistical Analysis All values are expressed as arithmetic mean \pm S.D. One-way ANOVA was used to determine the statistical significance.

\section{RESULTS AND DISCUSSION}

Astilbic acid is a type of triterpenoid that is widely distributed in higher plants. A. chinensis is a perennial herb that grows in Eurasia and eastern North America. The dried roots of $A$. chinensis have been used in Korean traditional medicine as an antipyretic, an analgesic, and a cough remedy. Recently, cytotoxic oleanane triterpenoids has been isolated from $A$. chinensis. ${ }^{19)}$ However, the underlying mechanisms of its antiinflammatory effects have not been reported. In an attempt to develop antiinflammatory compounds from $\mathrm{A}$. chinensis, astilbic acid, a known triterpenoid compound, was isolated from the $\mathrm{MeOH}-\mathrm{CH}_{2} \mathrm{Cl}_{2}$ extract.

Murakami et al. $^{20)}$ reported that BMMCs exhibited biphasic $\mathrm{PGD}_{2}$ biosynthetic responses over time, as well as cyclooxygenase (COX)-1-dependent immediate and COX-2dependent delayed responses. The immediate $\mathrm{PGD}_{2}$ generation, which occurs within $2 \mathrm{~h}$, is associated with the coupling of COX-1 and delayed $\mathrm{PGD}_{2}$ generation is observed after several hours of culture $(2-10 \mathrm{~h})$. In addition, it is associated with the de novo induction and function of COX-2 after

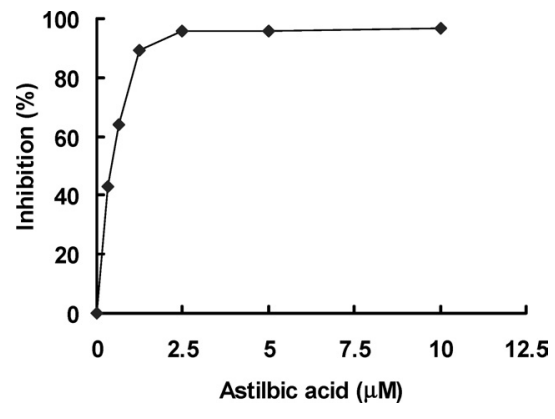

Fig. 2. Effect of Astilbic Acid on the Generation of LTC $_{4}$

BMMCs were preincubated for $30 \mathrm{~min}$ with the indicated concentrations of astilbic acid and then stimulated with $100 \mathrm{ng} / \mathrm{ml}$ of SCF for $15 \mathrm{~min}$. $\mathrm{LTC}_{4}$ released into the supernatant was quantified using an EIA kit.

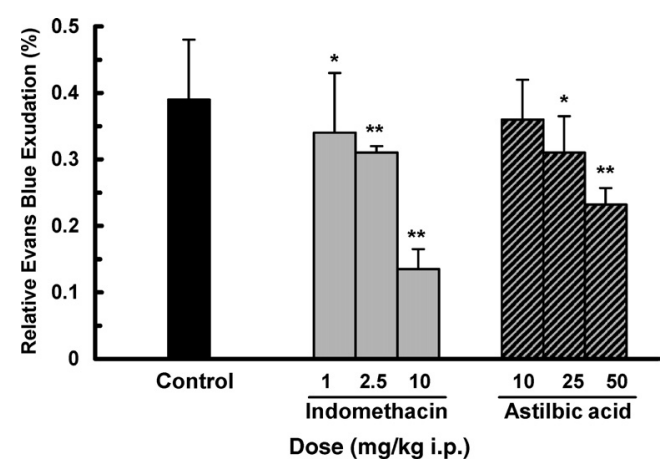

Fig. 3. Inhibition of IgE-Induced PCA Reaction by Astilbic Acid

The procedure for inducing the PCA reaction is described in Materials and Methods. Compounds $(10-50 \mathrm{mg} / \mathrm{kg})$ were administered intraperitoneally $30 \mathrm{~min}$ before $\mathrm{Ag}$ challenge. Indomethacin was used as a positive control. Data are expressed as arithmetic mean \pm S.D. $* p<0.05, * * p<0.01$, significantly different from control in the oneway ANOVA test.

stimulation with specific combinations of cytokines and LPS. $^{20)}$ This cell model also appears to be suitable for assessing the effect of 5-LOX inhibitors, since the immediate $\mathrm{LTC}_{4}$ generation elicited by IgE-dependent or cytokine-initiated stimulus occurs in BMMCs through 5-LOX. ${ }^{21)}$ Therefore the BMMC system is useful for screening selective COX$1 / \mathrm{COX}-2$ or 5 -LOX and COX-2/5-LOX dual inhibitors from various sources. Using this assay system, a new COX-2/ 5-LOX dual inhibitor was founded from Anthriscus sylvestris. ${ }^{22)}$ Astilbic acid inhibited the 5-LOX-dependent phases of $\mathrm{LTC}_{4}$ generation in BMMCs in a concentration-dependent manner with an $\mathrm{IC}_{50}$ value of $2.1 \mu \mathrm{M}$ (Fig. 2). However, this compound did not inhibit either COX-1 or COX-2dependent $\mathrm{PGD}_{2}$ generation up to a concentration of astilbic acid $30 \mu \mathrm{M}$ in this assay system (data not shown), indicating that astilbic acid selectively inhibits 5-LOX.

The effect of astilbic acid on the IgE-induced PCA reaction was examined using a rat model to determine its in vivo antiinflammatory activity. When $25 \mathrm{mg} / \mathrm{kg}$ of astilbic acid was injected intraperitoneally $1 \mathrm{~h}$ before the $\mathrm{Ag}$ challenge, the PCA reaction was suppressed by approximately $30 \%$ and the inhibition occurred in a concentration-dependent manner (Fig. 3). Under the same conditions, indomethacin $(10 \mathrm{mg} / \mathrm{kg})$, a nonsteroidal antiinflammatory drug, inhibited the PCA reaction by $60 \%$. Furthermore, the analgesic activity of astilbic acid was examined using the acetic acid-induced writhing test. The percentage protection afforded by the oral administration of astilbic acid $(0.4$ to $50 \mathrm{mg} / \mathrm{kg})$ 


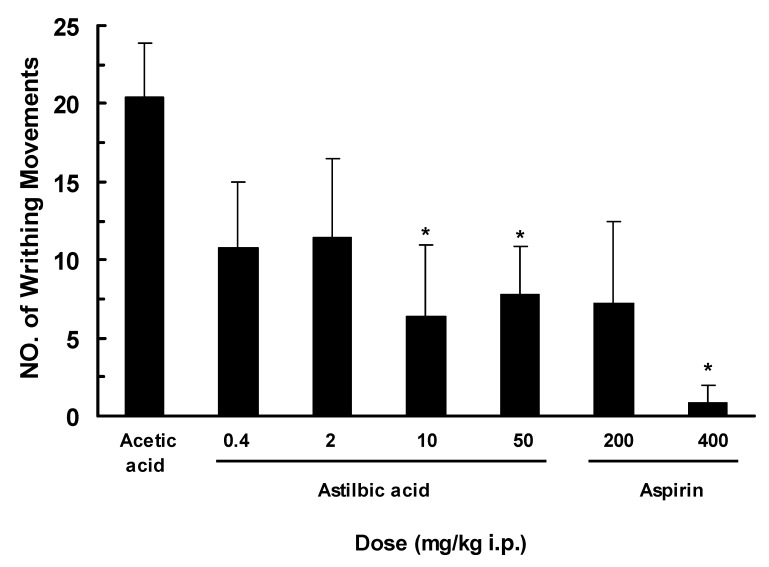

Fig. 4. Analgesic Activity of Astilbic Acid in Mice

The standard acetic acid-induced writhing test in mice was employed. The acetic acid-treated group writhed $20.1 \pm 5.4$ time in $10 \mathrm{~min} . * p<0.05$, significantly differen from the acetic acid-treated group. Data and bars represent arithmetic mean \pm S.D. $(n=5)$.

ranged from $44.1-61.8 \%$ (Fig. 4). Aspirin (200 mg/kg) also had a significant protective effect $(64.7 \%)$. A precise explanation for this result cannot yet be given, but it is believed that astilbic acid strongly inhibits 5-LOX activity because it is generally accepted that 5-LOX products induce the recruitment and activation of leukocytes, which lead to tissue damage and hyperalgesia. ${ }^{4,23,24)}$ Furthermore, LTC $_{4}$ attenuates the zymosan-induced peritoneal vascular permeability and IgEdependent PCA in mice. ${ }^{25}$

The lack of significant toxicity of this compound after oral administration indicates that it can be used safely in humans at moderate doses.

In conclusion, astilbic acid may be used as an antiinflammatory agent with analgesic activity because it, at least in part, inhibits 5-LOX activity. To the best of our knowledge, this is the first report of in vivo antiinflammatory activity of astilbic acid and provides a scientific basis for the medicinal use of this plant material in inflammatory disorders. The mechanism of the analgesic activity of astilbic acid is not well understood at present. Therefore it is necessary to clarify the selective 5-LOX inhibitors involved in the antinociceptive effects in animal model.

Acknowledgments This research was supported by a grant (PF0320302-00) from Plant Diversity Research Center of 21st Century Frontier Research Program funded by Ministry of Science and Technology of Korea government.

\section{REFERENCES}

1) Lewis R. A., Austen K. F., Soberman R. J., N. Engl. J. Med., 323, 645-655 (1990).

2) Henderson W. R., Jr., Ann. Intern. Med., 121, 684-697 (1994).

3) McMillan R. M., Walker E. R., Trends Pharmacol. Sci., 13, 323-330 (1992).

4) Levine J. D., Lau W., Kwiat G., Science, 225, 743-745 (1984).

5) Levine J. D., Lam D., Taiwo Y. O., Donatoni P., Goetzl E. J., Proc. Natl. Acad. Sci. U.S.A., 83, 5331-5334 (1986).

6) Cunha J. M., Sachs D., Canetti C. A., Poole S., Ferreira S. H., Cunha F. Q., Br. J. Pharmacol., 139, 1135-1145 (2003).

7) Petric R., Nicholson D. W., Ford-Hutchinson A. W., Biochim. Biophys. Acta, 1254, 207-215 (1995).

8) Simonson M. S., Dunn M., J. Kidney. Int., 30, 524-531 (1986).

9) Massoumi R., Nielsen C. K., Azemovic D., Sjolander A., Exp. Cell Res., 289, 342-351 (2003).

10) Panettieri R. A., Tan E. M., Ciocca V., Luttmann M. A., Leonard T. B., Hay D. W., Am. J. Respir. Cell Mol. Biol., 19, 453-461 (1998).

11) Brady H. R., Lamas S., Papayianni A., Takata S., Matsubara M., Marsden P. A., Am. J. Physiol., 268, F1-F12 (1995).

12) He W., Pelletier J. P., Martel-Pelletier J., Laufer S., Di Battista J. A., J. Rheumatol., 29, 546-553 (2002).

13) Sastry B. S., Rao E. V., Indian J. Chem., 15B, 494-495 (1977).

14) Takahashi K., Kanayama K., Tanabe Y., Takani M., Chem. Pharm. Bull., 20, 2106-2111 (1972).

15) Bingham C. O., III, Murakami M., Fujishima H., Hunt J. E., Austen K. F., Arm J. P., J. Biol. Chem., 271, 25936-25944 (1996).

16) Murakami M., Kambe T., Shimbara S., Kudo I., J. Biol. Chem., 274, 3103-3115 (1999).

17) Katayama S., Shionoya H., Ohtake S., Microbiol. Immunol., 22, 89 101 (1978).

18) Bentley G. A., Newton S. H., Star J., Br. J. Pharm., 79, 125-134 (1983).

19) Sun H. X., Ye Y. P., Pan Y. J., J. Ethnopharmacol., 90, 261-265 (2004).

20) Murakami M., Matsumoto R., Austen K. F., Arm J. P., J. Biol. Chem., 269, 22269-22285 (1994).

21) Murakami M., Austen K. F., Arm J. P., J. Exp. Med., 182, 197-206 (1995).

22) Lee S. H., Son M. J., Ju H. K., Lin C. X., Moon T. C., Choi H. G., Son J. K., Chang H. W., Biol. Pharm. Bull., 27, 786-788 (2004).

23) Bennett G., al-Rashed S., Hoult J. R., Brain S. D., Pain , 77, 315-322 (1998).

24) Amann R., Schuligoi R., Lanz I., Peskar B. A., Eur. J. Pharmacol., 306, 89-91 (1996).

25) Kanaoka Y., Maekawa A., Penrose J. F., Austen K. F., Lam B. K., J. Biol. Chem., 276, 22608-22613 (2001). 